\title{
Parallel poly(A) homo- and hetero-duplex formation detection with an adapted DNA nanoswitch technique
}

\author{
MARTHA ANNE G. PICKARD, ${ }^{1}$ KARL B. BRYLOW, ${ }^{1}$ LILY A. CISCO, ${ }^{1,3}$ MATTHEW R. ANECELLE, ${ }^{1}$ \\ MACKENZIE L. PERSHUN, ${ }^{1}$ ARUN RICHARD CHANDRASEKARAN, ${ }^{2}$ KEN HALVORSEN, ${ }^{2}$ \\ and MICHAEL L. GLEGHORN ${ }^{1}$ \\ ${ }^{1}$ School of Chemistry and Materials Science, Rochester Institute of Technology, Rochester, New York 14623, USA \\ ${ }^{2}$ The RNA Institute, University at Albany, State University of New York, Albany, New York 12222, USA
}

\begin{abstract}
Polyriboadenylic [poly(rA)] strands of sufficient length form parallel double helices in acidic and/or ammonium-containing conditions. Poly(rA) duplexes in acidic conditions are held together by $\mathrm{A}^{+}-\mathrm{A}^{+}$base-pairing also involving base interactions with the phosphate backbone. Traditional UV-melting studies of parallel poly(A) duplexes have typically examined homoduplex formation of a single nucleic acid species in solution. We have adapted a technique utilizing a DNA nanoswitch that detects interaction of two different strands either with similar or differing lengths or modifications. Our method detected parallel duplex formation as a function of length, chemical modifications, and $\mathrm{pH}$, and at a sensitivity that required over 100 -fold less concentration of sample than prior UV-melting methods. While parallel polyriboadenylic acid and poly-2'O-methyl-adenylic acid homo-duplexes formed, we did not detect homo-duplexes of polydeoxyriboadenylic acid strands or poly-locked nucleic acid (LNA)-adenylic strands. Importantly however, a poly-locked nucleic acid (LNA)-adenylic strand, as well as a poly-2'-O-methyl-adenylic strand, formed a hetero-duplex with a polyriboadenylic strand. Overall, our work validates a new tool for studying parallel duplexes and reveals fundamental properties of poly(A) parallel duplex formation. Parallel duplexes may find use in DNA nanotechnology and in molecular biology applications such as a potential poly(rA) tail capture tool as an alternative to traditional oligo(dT) based purification.
\end{abstract}

Keywords: poly(A); polyadenylic; parallel; nanoswitch; adenine; LNA

\section{INTRODUCTION}

In acidic conditions, and/or in the presence of ammonium ions, ribonucleic acid strands containing all adenine bases of 6 nt or longer [i.e., polyriboadenylic acid or poly $(r A)$ ] will bind one another and form parallel homo-stranded righthanded double helices (Fig. 1; Rich et al. 1961; Brahms et al. 1966; Safaee et al. 2013; Gleghorn et al. 2016). In contrast, B-form DNA, A-form RNA, and A-form heterostranded RNA-DNA double helices have strands that are antiparallel to one another (Fig. 2A). Two different X-ray crystal structures of parallel poly $(r A)$ duplexes have been solved and validated a long-standing structural model that had been built from fiber diffraction data (Rich et al. 1961; Safaee et al. 2013; Gleghorn et al. 2016). These structural models depict a parallel poly(rA) duplex where each adenine C6-attached amino group nitrogen (N6) hydrogen bonds to the N7 of the symmetrically paired aden-

\footnotetext{
${ }^{3}$ Present address: Department of Pharmacology and Physiology, School of Medicine and Dentistry, University of Rochester, Rochester, NY 14642, USA

Corresponding author: mlgsch@rit.edu

Article is online at http://www.rnajournal.org/cgi/doi/10.1261/rna. 075408.120.
}

osine from the opposite strand (Fig. 1B,C; Rich et al. 1961; Safaee et al. 2013; Gleghorn et al. 2016). Additionally, hydrogen bonds exist between the adenine amino group N6 and a non-bridging oxygen from a phosphate of the opposite strand. Importantly, the parallel duplex is stabilized by $\mathrm{N} 1$ protonation in acidic conditions (i.e., $\mathrm{A}^{+}$, where " +" denotes a protonated adenine) or under neutral $\mathrm{pH}$ in the presence of an N1- and non-bridging phosphate oxygen-coordinated ammonium ion (Fig. 1B,C; Rich et al. 1961; Safaee et al. 2013; Gleghorn et al. 2016). As such, poly $(\mathrm{rA})$ duplexes have melting temperatures that increase with strand length, acidity, and ammonium ion concentration (Safaee et al. 2013). Although there are examples of antiparallel A-A pairing in the context of helices stabilized by other pairing or stabilizing molecules (Baeyens et al. 1996; Persil et al. 2004; Xing et al. 2005; Jain et al. 2008; Joung et al. 2009; Devi et al. 2015), when nucleic acid

(C) 2020 Pickard et al. This article is distributed exclusively by the RNA Society for the first 12 months after the full-issue publication date (see http://rnajournal.cshlp.org/site/misc/terms.xhtml). After 12 months, it is available under a Creative Commons License (AttributionNonCommercial 4.0 International), as described at http:// creativecommons.org/licenses/by-nc/4.0/. 
A

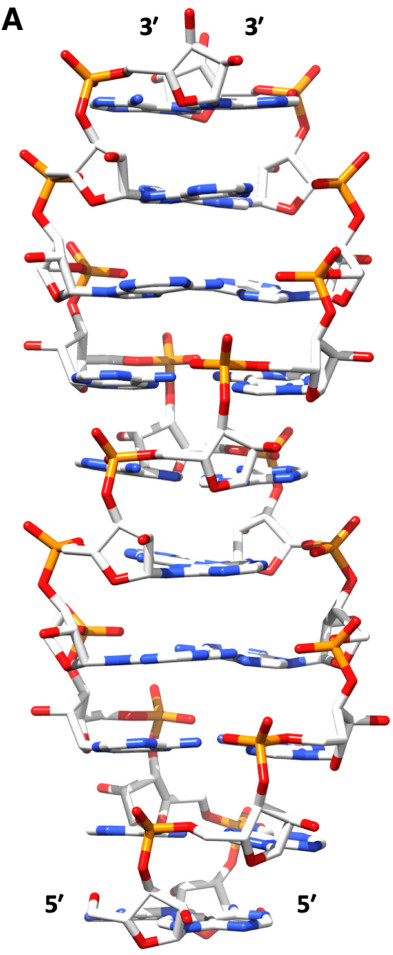

B

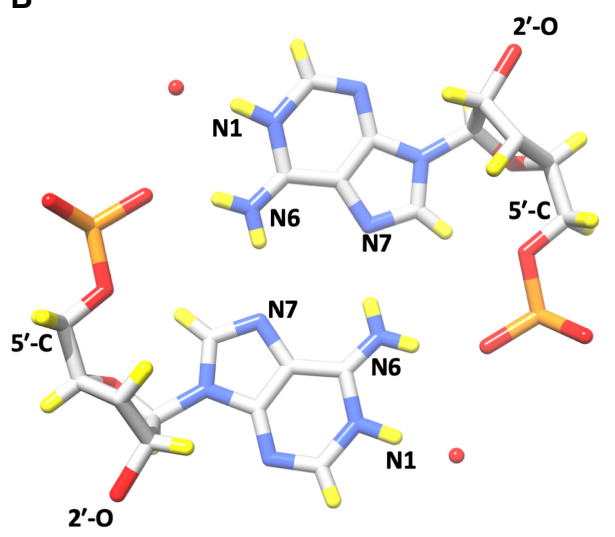

C

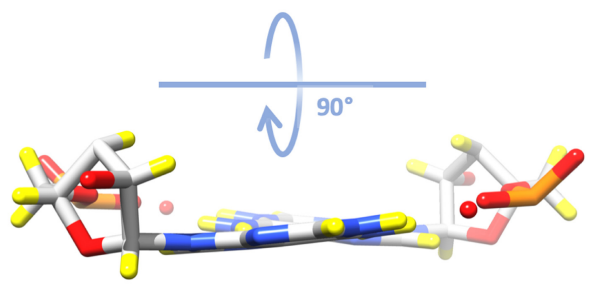

FIGURE 1. Known poly(rA) parallel duplex helix structure and pairing interactions. (A) Poly(rA) parallel duplex structure showing the 10-bp duplex region of a neutral $\mathrm{pH}$ and ammonium induced structure (PDB 4JRD) that has structural similarity to the acidic induced structure. Solvent and ammonium ion molecules are not shown. (B) A specific protonated A-A pair of the poly $(\mathrm{rA})$ helix structure (PDB $5 \mathrm{~K} 8 \mathrm{H})$ at acidic $\mathrm{pH}$, but now modeled with a hydrogen in the N1 position (not originally modeled, rather inferred). (C) A $\sim 90^{\circ}$ rotation of " $B$ " to illustrate a side-view perspective of a single intermolecular base pair. Atom colors are: carbons (white), oxygens (red), phosphorus (orange), nitrogens (blue), and hydrogens (yellow), not shown in $A$. An N1-proximal water molecule is shown in panels $B$ and $C$. Images were generated with UCSF Chimera software (Pettersen et al. 2004).

strands are only poly $(A)$, only the parallel orientation is known to form a duplex.

Copp et al. (2017) have analyzed strand interactions in poly $(\mathrm{rA})$ parallel duplexes when the component strands were identical in nucleic acid sequence and length. They used UV-melting and native gel analyses at different $\mathrm{pH}$ values to test for homo-duplex formation when modified sugars were placed in key locations of the strand (Copp et al. 2017). In that study, duplex stability was enhanced in acidic conditions when 2'-O-methylated sugars of adenosine (Fig. 2B) were incorporated within poly(rA)-containing strands, and in ammonium-containing conditions with the presence of $2^{\prime}$-fluoro-ribose $\left(2^{\prime}-F\right)$ sugars. However, 2'-deoxyribose adenosines (dAs) within a poly ( $\mathrm{rA}$ )-containing strand reduced duplex thermal stability and poly $(\mathrm{dA})$ did not form a homo-duplex, contrary to a prior report (Chakraborty et al. 2009; Copp et al. 2017).

Other groups have studied the influence of locked nucleic acids (LNAs) on parallel duplex formation (Szabat et al. 2015). LNAs comprised of 2'-O-4'-C-methylene- $\beta$-Dribofuranosyl sugars having a linking carbon between the

2' oxygen and $4^{\prime}$ carbon (Fig. 2B) that forces a C3'-endo ("north" or "N") sugar pucker, a property of sugars in A-form antiparallel WatsonCrick paired RNA helices and observed in parallel poly $(A)$ duplex structures (Vester and Wengel 2004; Safaee et al. 2013; Gleghorn et al. 2016). Addition of LNAs to nucleic acid sequences have been exploited for a number of molecular biology applications that require binding of small nucleic acid strands to, for example, messenger RNA targets for targeted down-regulation (Vester and Wengel 2004). The enhancement that LNAs provide is an increased thermal stability of the resulting antiparallel duplex (Vester and Wengel 2004). Various other nucleic acid parallel duplex structures exist in addition to parallel poly(A) duplexes (Day et al. 2014; Szabat and Kierzek 2017). The effect of LNA incorporation studies on nucleic acid complexes with strands in parallel orientation include a study revealing increased triplex stability at physiological $\mathrm{pH}$, versus natural formation requiring a more acidic $\mathrm{pH}$, when LNA-containing triplex forming strands (TFOs) form Hoogsteen base pairs in a parallel orientation to a strand that is part of a DNA antiparallel duplex (Obika et al. 2001; Vester and Wengel 2004). Acid induced i-motif structures comprised of $\mathrm{C}_{-} \mathrm{C}^{+}$pairs can form with some substitution of DNA with LNA residues (Kumar et al. 2007). We are unaware of any prior studies examining $L N A$ in parallel poly $(A)$ duplex formation prior to what we report here.

Formation of parallel duplex structures are studied for their role in regulation of biological processes (Szabat and Kierzek 2017) and potential uses in mRNA targeting strategies (Jain et al. 2008). Recent discovery of the presence of the i-motif structure in the cell (Zeraati et al. 2018) points to potential roles of other unusual nucleic acid structures such as poly $(\mathrm{rA})$ parallel duplexes in biology. A published hypothesis postulated that protein-mediated protonation of mRNA poly $(r A)$ tails generated by polyadenylation can reach sufficient length to loop back on themselves, forming parallel poly $(r A)$ duplexes that could inhibit further $3^{\prime}$ polyadenylation of mRNAs; potential poly $(r A)$ duplex roles regarding regulation of poly $(A)$ binding protein (PAB) and stabilization of mRNA were also discussed (Zarudnaya and Hovorun 1999). We speculate that poly $(\mathrm{rA})$ tails could be an evolved sensor for acidic 
A Known duplexes

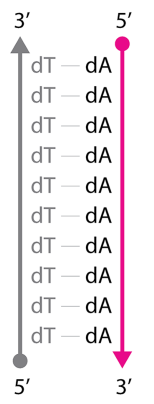

Antiparallel B-form DNA duplex

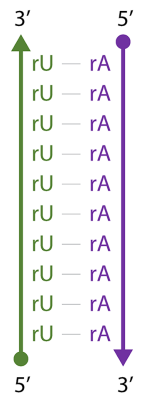

Antiparallel A-form

RNA duplex

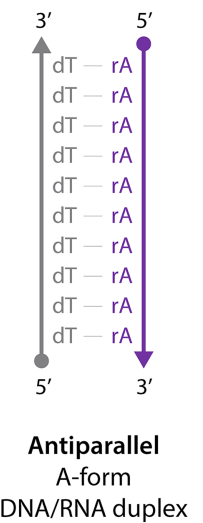

B

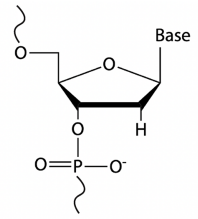

DNA

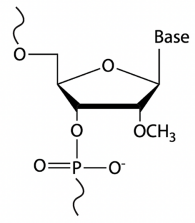

2'-O-methyl RNA

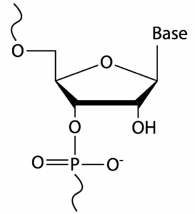

RNA

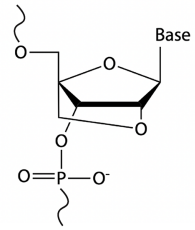

LNA

\section{Testable interactions}
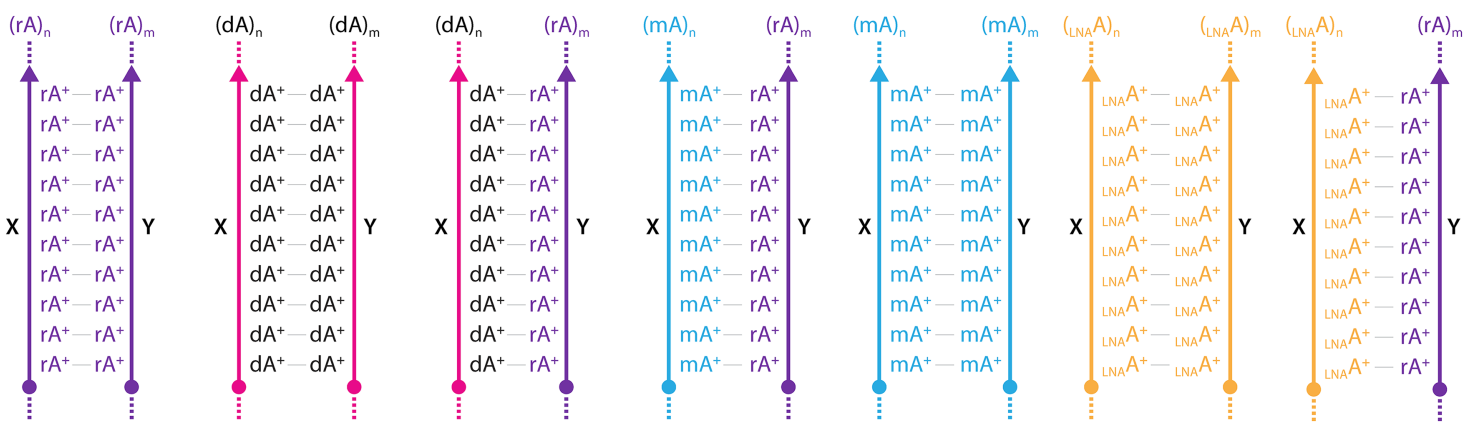

FIGURE 2. Known and testable interactions involving poly(A) strands. (A) Known and example antiparallel and parallel duplexes are shown for comparison. Note that "+" indicates a protonated state relative to a neutral pH state. (B) The variety of sugar modifications tested in this study. (C) Examples of some DNA nanoswitch testable parallel hetero- and homo-poly(A) duplex formations. The " $n$ " and " $m$ " notations indicate that strands can be of specific testable lengths.

internal cellular stress, possibly forming duplexes composed of strands from different mRNA poly(rA) tails in trans, causing mRNA to cluster together and halting their translation, which all could be undone when $\mathrm{pH}$ is restored to near neutral $\mathrm{pH}$. It is known that mRNAs accumulate in cells upon stress, and the possibility has been suggested that PABs that bind single-stranded poly $(\mathrm{rA})$ serve cells to prevent poly $(\mathrm{r} A)$-duplex mediated clustering (Safaee et al. 2013). In the context of DNA nanotechnology, nonWatson-Crick base-pairing is used in many devices for biosensing and triggered drug release purposes (Yatsunyk et al. 2014). The $\mathrm{pH}$ responsive formation of poly(A) parallel duplexes makes them potential candidates for $\mathrm{pH}$ sensing switches and in stimuli-responsive nanostructures.

Parallel poly(A) duplex formation has often been studied using a single species (i.e., all having the same sequence and length) of nucleic acid strand in solution and using techniques such as UV melting, circular dichroism (CD), and native gel separations (Brahms et al. 1966; Safaee et al. 2013; Copp et al. 2017). However, there are two major drawbacks to existing methods. (1) When testing hetero-dimeric interactions of two different poly(A)-con- taining strands in solution, a profound inherent problem is that results are complicated due to homo-dimers of each strand additionally forming in the tested conditions. (2) Techniques such as UV melting and CD require high concentrations of the sample. As a solution to these problems we have developed and report here an adapted use of a DNA nanoswitch to specifically detect interaction of two different strands without detecting unwanted interactions. Concentrations we used for detection are far lower than typical UV melting experiments.

To validate our nanoswitch-based parallel poly(A) duplex detection method, we tested if our results mimicked those expected from in-solution studies. Validating results showed that (i) lower $\mathrm{pH}$ values, those nearest (yet above) the adenine $\mathrm{N} 1 \mathrm{pKa}(\mathrm{pH} 4.5$ and 5.0), and also known to induce poly $(\mathrm{r} A)$ duplex formation in solution, produced positive nanoswitch detection signal indicating poly(rA) homo-duplex formation whereas $\mathrm{pH} 6.0 \mathrm{did}$ not, and (ii) more signal was produced the longer the poly $(\mathrm{rA})$ homoduplex tested (Brahms et al. 1966; Safaee et al. 2013). To clarify conflicting reports in the literature regarding poly (dA) parallel homo-duplex formation, we tested and found 
no positive nanoswitch detection signal. We did however find that poly(A) strands modified with 2'-O-methylated ribose sugars [Fig. 2B; poly $(m A)$ ] produced nanoswitch-based detection signal higher than for the poly ( $r A)$ duplexes of the same length. The latter two findings both agree with the findings of Copp et al. (2017) and add additional support to the validity of our method. Given that $3^{\prime}$-endo sugar pucker is observed in all known determined structures of parallel poly(A) duplexes (Safaee et al. 2013; Gleghorn et al. 2016; Copp et al. 2017) and that LNAs are trapped into a 3'-endo sugar pucker configuration, we wanted to know if poly(LNAA) could also form parallel duplexes. Using the hetero-duplex detection ability of our method, we observed that poly(LNAA)-poly(rA) duplex formation produced a stronger relative signal than poly(rA)-only duplexes, yet surprisingly poly(LNAA)poly(LNAA) duplexes did not form. Our results provide insight into sugar pucker and general structure requirements for $\operatorname{poly}(A)$ parallel helix formation. Our assay provides a new way to study a variety (Fig. 2C) of complex interactions, and our results may have potential applications in DNA nanotechnology and molecular biology.

\section{RESULTS}

\section{Parallel poly(A) duplex detection with a DNA nanoswitch}

\section{Design of testable interaction regions to use with the DNA nanoswitch}

A recent bioanalysis tool called a DNA nanoswitch can be used to visually detect binding of a molecule or molecules of interest through readout of altered DNA migration after agarose gel separation (Koussa et al. 2015; Chandrasekaran et al. 2016, 2017, 2019). For example, DNA nanoswitches can detect the presence of singlestranded small RNAs of a specific sequence from cellular total RNA in a highly sensitive manner (Chandrasekaran et al. 2019). The DNA nanoswitch that we use here is made of a linearized single-strand of M13 bacteriophage DNA with annealed reverse complement oligonucleotides duplexed along the length of M13 DNA, with the exception of extended single-stranded detector arm regions that are not duplexed (Fig. 3A). To detect parallel duplex interactions, we designed chimeric oligonucleotides that contained a 14 nt DNA region that reverse complements to a detector arm ("holding regions" $d 1$ and $d 2$ in Fig. $3 \mathrm{~B})$, while the remaining portion of the oligo was changed to a variety of all adenine-containing nucleotides with different testable ribose, 2'-deoxyribose, or other sugar moiety modifications ("interacting regions" $X$ and $Y$ in Fig. 3B). Sequences for these variations are listed in Table 1. To test for parallel poly(rA) homo-duplex formation for example, two different test strands were used with the nanoswitch. One strand had at its $3^{\prime}$ side, a DNA region (d1) that binds to detector arm $1\left(\mathrm{~d} 1^{*}\right)$ on the nanoswitch, and at the $5^{\prime}$ side of the strand had a number of sequential rAs [i.e., poly(rA), "X"] (Fig. 3B). The other tested strand contained at its $5^{\prime}$ side the reverse complement DNA sequence $(d 2)$ to pair with detector arm 2 sequence $\left(d 2^{*}\right)$, and at the $3^{\prime}$ side of this strand was a poly(rA) region (i.e., " $Y$ ") that was tested for interaction with " $X$ " (Fig. 3B). If $X$ and $Y$ formed a parallel duplex, then this slows migration of the nanoswitch "on" state upon agarose gel separation and generated a positive detection for the DNA nanoswitch (Fig. 3C). In this way, the detector bound portions of tested oligos form antiparallel Watson-Crick base pairs with the DNA nanoswitch detector arms while simultaneously permitting formation of parallel poly $(A)$ duplexes of the other 
TABLE 1. Oligonucleotides used in these studies

\begin{tabular}{|c|c|}
\hline DNA/RNA Oligomer & Sequence $5^{\prime}-\rightarrow 3^{\prime}$ \\
\hline$K 28(d 1+d 2)$ & GACACGGTCTCATGGCCCTTCAATCTGA \\
\hline d1 & GCCCTTCAATCTGA \\
\hline d2 & GACACGGTCTCATG \\
\hline d1 ra8 & $(\mathrm{rA})_{8}$ GCCCTTCAATCTGA \\
\hline d2 rA8 & GACACGGTCTCATG $(r A)_{8}$ \\
\hline d1 rA16 & $(\mathrm{rA})_{16}$ GCCCTTCAATCTGA \\
\hline d2 rA16 & GACACGGTCTCATG $(\mathrm{rA})_{16}$ \\
\hline d1 rA24 & $(\mathrm{rA})_{24}$ GCCCTTCAATCTGA \\
\hline d2 rA24 & GACACGGTCTCATG $(\mathrm{rA})_{24}$ \\
\hline d1 dA8 & $(\mathrm{dA})_{8}$ GCCCTTCAATCTGA \\
\hline d2 dA8 & $\underline{\text { GACACGGTCTCATG }(\mathrm{dA})_{8}}$ \\
\hline d1 dA16 & $(\mathrm{dA})_{16}$ GCCCTTCAATCTGA \\
\hline d2 dA16 & $\underline{\text { GACACGGTCTCATG }(\mathrm{dA})_{16}}$ \\
\hline d1 dA24 & $(\mathrm{dA})_{24}$ GCCCTTCAATCTGA \\
\hline d2 dA24 & $\underline{\text { GACACGGTCTCATG }(\mathrm{dA})_{24}}$ \\
\hline d1 mA8 & $(\mathrm{mA})_{8} \mathrm{GCCCTTCAATCTGA}$ \\
\hline d2 mA8 & $\underline{\text { GACACGGTCTCATG }}(\mathrm{mA})_{8}$ \\
\hline d1 mA16 & $(\mathrm{mA})_{16} \mathrm{GCCCTTCAATCTGA}$ \\
\hline d2 mA16 & GACACGGTCTCATG $(\mathrm{mA})_{16}$ \\
\hline d1 mA24 & $(\mathrm{mA})_{24}$ GCCCTTCAATCTGA \\
\hline d2 mA24 & GACACGGTCTCATG $(\mathrm{mA})_{24}$ \\
\hline d1 rA1-LNA15 & $\left({ }_{\text {LNA }} \mathrm{A}\right)_{15}$ rAGCCCTTCAATCTGA \\
\hline d2 rA1-LNA15 & $\underline{\text { GACACGGTCTCATGrA }}\left(\left(_{\text {LNA }} A\right)_{15}\right.$ \\
\hline d2 rA8-LNA8 & GACACGGTCTCATG $\left(r A_{\text {LNA }} A\right)_{8}$ \\
\hline
\end{tabular}

Names of each DNA, RNA, or DNA/RNA chimera are indicated. Underlined regions of each sequence indicate the region that forms an antiparallel reverse complement to respective detector regions on the nanoswitch. Oligos standard to the DNA nanoswitch are not shown (Chandrasekaran et al. 2016).

tested $X$ and $Y$ components of the strands using nonWatson-Crick pairing (Fig. 3A, inset; Safaee et al. 2013; Gleghorn et al. 2016). By simply leaving the respective d1 or d2 DNA regions intact, but changing the compositions of $X$ and $Y$ on these chimeric nucleic acids, we were able to test for a variety of interactions.

\section{Agarose gel separations}

Since parallel poly $(\mathrm{r} A)$ homo-duplexes have long been known to form in acidic conditions (Rich et al. 1961; Brahms et al. 1966) but not at neutral pH (i.e., unless in the presence of ammonium ions), we had to validate that DNA nanoswitch-detected interactions were $\mathrm{pH}$ dependent, as evidence that we are indeed detecting parallel duplexes. To achieve this, incubations of nucleic acid components, and the subsequent agarose separations had to be at the same $\mathrm{pH}$; otherwise, a complex that formed in acidic incubation conditions might fall apart if the agarose gel was at near neutral pH conditions, for example, prior to detection. Another important consideration was to not over-incubate complexes prior to detection in acidic conditions due to potential depurination effects.

To decrease heat generation during electrophoresis in our conditions to that below melting temperatures of at least the longest poly(rA) duplexes tested (Brahms et al. 1966; Safaee et al. 2013), we had to perform separations more slowly than traditional $1 \times$ TBE agarose gels, in the cold (refrigerator) and surrounded by ice and ice packs. Using an infra-red heat gun and periodically measuring the temperature at 20-min intervals over $260 \mathrm{~min}$ of $\mathrm{pH}$ 4.5 and $\mathrm{pH} 5.0$ agarose gel separations, the maximum temperature recorded was $7.5^{\circ} \mathrm{C}$, and $9.3^{\circ} \mathrm{C}$, respectively (data not shown).

\section{Validation of DNA nanoswitch detection of known $\mathrm{pH}$ dependent poly(A) duplex interactions}

Poly(rA) homo-duplexes form as a function of length, acidity, and ammonium ion concentration (Brahms et al. 1966; Safaee et al. 2013). Poly(rA) as small as $r A_{b}$ have been shown to form parallel homo-duplexes and the thermal stability of these complexes increases as the length of strands in the duplex increase (Brahms et al. 1966; Safaee et al. 2013), likely due to increased hydrogen bonding interactions. Additionally, parallel poly(rA) duplexes are more thermally stable as $\mathrm{pH}$ decreases from neutral pH (Brahms et al. 1966; Safaee et al. 2013). Poly(mA), that is, 2'-O-methylated, parallel duplexes with eight possible $\mathrm{A}^{+}-\mathrm{A}^{+}$pairs ( $\mathrm{dT}_{1}-\mathrm{mA}_{8}$ strands) form at $\mathrm{pH} 4.0$ and have a higher melting temperature $\left(+10^{\circ} \mathrm{C}\right)$ than poly $(\mathrm{rA})$ duplexes $\left(\mathrm{dT}_{1}-\mathrm{rA}_{8}\right.$ strands) of a similar length (Copp et al. 2017). To validate that DNA nanoswitch detection produced signal for the known low-pH induced parallel poly (A) homo-duplex formation, while not producing signals at higher $\mathrm{pH}$, we tested for strand interactions at $\mathrm{pH} 4.5$, 5.0, and 6.0. As a negative control, we used two strands with sequences $\mathrm{d} 1$ and $\mathrm{d} 2$ that bind to respective $\mathrm{d} 1$ * and $\mathrm{d} 2 *$ detectors of the nanoswitch separately, verifying that the "holding regions" (Fig. 3B) alone do not generate looping of the DNA nanoswitch (Fig. 4A, top). We used a 28 nucleotide (nt) DNA oligo "K28" as a positive control (Chandrasekaran et al. 2016), which contains 14 bases on each side for binding each of the two detector arms (Fig. 4A, bottom). K28 binding causes a looped-out structure to form that slows migration on an agarose gel of this "on" state DNA nanoswitch relative to an undetected "off" state (Fig. 4A, inset).

To determine if our method produced a signal readout reflective of parallel duplex length, knowing that longer lengths are more thermally stable (Brahms et al. 1966; 
A

Negative control ( - )

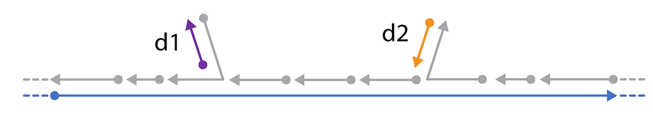

Positive control $(+)$
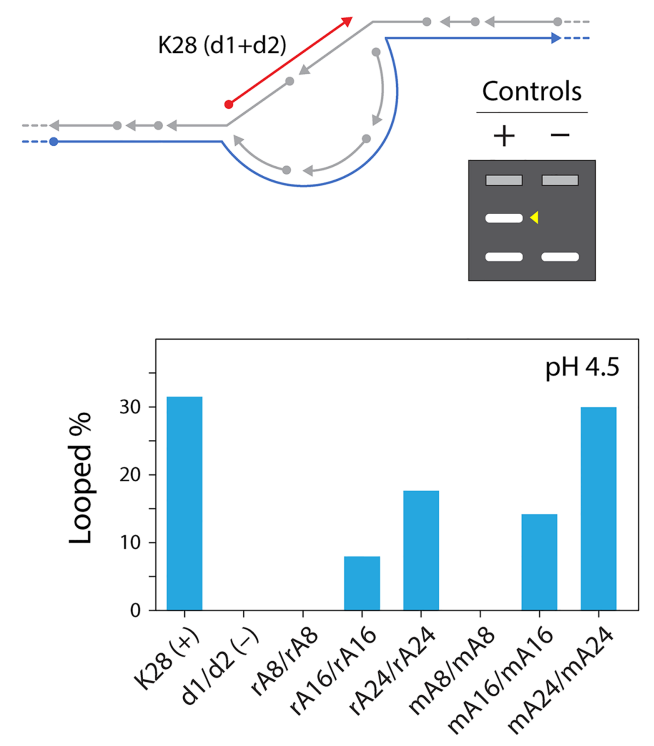

B
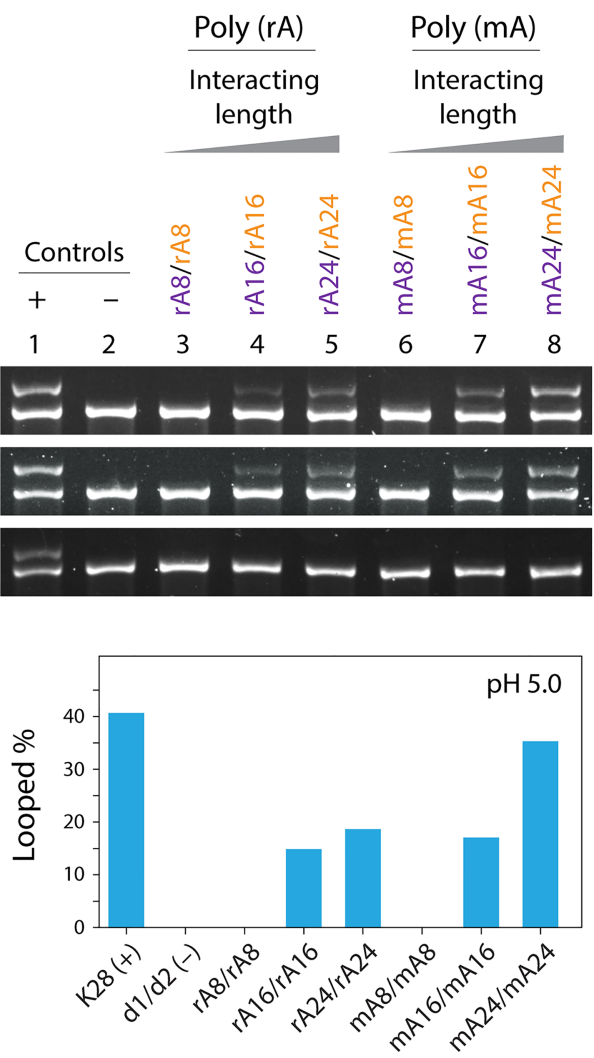

FIGURE 4. Parallel poly(A) duplexes are detected by a DNA nanoswitch in a pH dependent manner. (A) Negative and positive controls used in this study. For the positive (+) control scenario, we used an oligonucleotide sequence (K28) with symmetric 14 base-pairing with each detector region (Chandrasekaran et al. 2016). The full K28 sequence combined the $\mathrm{d} 1$ and $\mathrm{d} 2$ sequences, complementary to the detector arms $\mathrm{d} 1$ * and $\mathrm{d} 2 *$ described in Figure 3. For a negative control, we added two oligonucleotides (d1 and d2) that bind separately to detectors and quench the nanoswitch and thus avoid loop formation. Representative expected gel image with the positive and negative controls is shown as an inset. The positive "detection" band is indicated by a yellow arrow. $(B)$ Testing poly $(\mathrm{r} A)$ and poly $(\mathrm{mA})$ interactions. Agarose gels with lanes indicated for the strand interactions tested and the $\mathrm{pH}$ used for each assay. Interaction regions bound to detectors 1 and 2 are indicated in purple and orange, respectively, on top of each lane. (C) Quantified results of parallel duplex formation at different $\mathrm{pH}$ values for different lengths of poly( $\mathrm{r} A)$ and poly $(m A)$ strands tested.

Safaee et al. 2013), we first designed oligonucleotides (Table 1) to test for interaction and complex formation in different lengths of poly(rA)-poly(rA) and poly(mA)-poly $(\mathrm{mA})$ sequences. We tested 8-, 16- and 24-nt versions of these strands by creating interaction regions of similar lengths on strands bound to both detectors: rA8-rA8, rA16-rA16, rA24-rA24, mA8-mA8, mA16-mA16, and $m A 24-m A 24$, where the first segment denotes the type of nucleotide and length of interacting region in detector 1 (purple in Fig. 4B) and the second segment denotes those attached to detector 2 (orange in Fig. 4B). In all shown tested $\mathrm{pH}$ values, single-stranded positive control K28 was detected by the DNA nanoswitch, and negative control strands $(\mathrm{d} 1 / \mathrm{d} 2)$, which are reverse complemented DNA to the detector arms, were not detected (Fig. 4B). This indicates that the "on" state is due to bridging detector arms and validates the functionality of the nanoswitch at the different $\mathrm{pH}$ values tested. All our subsequent DNA nanoswitch experiments include these positive and negative controls as quality controls and as such have sim- ilar readouts. Importantly, interactions with the strongest signal in the two most acidic $\mathrm{pH}$ values tested were those of the greatest length and known to interact in acidic conditions, rA24-rA24 and mA24-mA24, and these homo-duplexes are not visible at pH 6.0 (Fig. 4B,C). These results validate the utility of the DNA nanoswitch in detecting parallel poly $(A)$ duplexes as a function of $\mathrm{pH}$ since parallel poly (rA) and poly (mA) homo-duplexes formed at $\mathrm{pH} 4.5$ and 5.0, but not at $\mathrm{pH}$ 6.0. As expected, a general trend of decreased detection was visualized as the size of homo-dimers decreased to 16 (rA16-rA16 and mA16-mA16) pairs, and then to an undetected 8 (rA8-rA8 and mA8$\mathrm{mA} 8$ ) pairs in each acidic condition tested (Fig. 4C).

\section{Increased sensitivity of parallel poly(A) duplex detection compared to traditional UV melting studies}

A known advantage of nucleic acid detection with a DNA nanoswitch is its high sensitivity (Koussa et al. 2015; Chandrasekaran et al. 2016). The nanoswitch itself is 
relatively large $(\sim 7 \mathrm{kbp})$ compared to what it is detecting (8-24 bp). Thus when a single molecule is detected, the large mass of the entire nanoswitch shifts position on the gel due to the change in topology (linear to looped) and binds to many molecules of DNA interacting dyes like GelRed to produce a signal much stronger than what could be obtained from staining just the single detected nucleic acid complex alone (i.e., the parallel poly(A) duplex) (Koussa et al. 2015; Chandrasekaran et al. 2016). Traditional parallel poly(A) duplex detection uses UV melting which requires a significant amount of material to produce an absorbance at $260 \mathrm{~nm}\left(\mathrm{~A}_{260}\right)$ that permits the detection of duplex (lower absorbance) and single-stranded (higher absorbance) species in solution (Brahms et al. 1966; Safaee et al. 2013; Copp et al. 2017). UV-melting experiments typically start at an $\mathrm{A}_{260}$ of 0.5 and melt to an $\mathrm{A}_{260}$ of 0.8 (Brahms et al. 1966; Safaee et al. 2013; Copp et al. 2017). For an rA24 strand for example, which is $3.43 \mathrm{nmole} / \mathrm{OD}_{260}$, an $\mathrm{A}_{260}$ of 0.8 is $2.74 \mu \mathrm{M}$. Our experiments were carried out with a $10.42 \mathrm{nM}$ final concentration of each separate strand. Even if we, for the sake of comparison, divided the concentration of strands for a typical UVmelting study in half considering that only strands of the same rA24 sequence are used rather than two different strands as in our method, our method still requires over 130 times less concentration of strands for parallel duplex detection than a typical UV melting study.

\section{Poly(dA) duplexes are not detected by the DNA nanoswitch detection method in conditions that detect poly(rA) duplex formation}

Recent UV melting studies and native gel analysis studies by Copp et al. (2017) showed that the introduction of dA within an otherwise strand of $\mathrm{rA}$ or $\mathrm{mA}$ nucleotides, decreased relative duplex stability in acidic and ammonium-containing solutions, and a dA-only strand did not form a duplex. These studies appear to invalidate a prior study that suggested poly(dA) strands form parallel duplexes (Chakraborty et al. 2009). To test the formation of poly(dA) homo-duplexes, we added $\mathrm{dA} 8, \mathrm{dA} 16$, and $\mathrm{dA} 24$ to $\mathrm{d} 1$ and $\mathrm{d} 2$ sequences and carried out a DNA nanoswitch detection (Fig. 5) at pH 4.5. Although $r A 16$ and $r A 24$ homo-duplexes were detected at $\mathrm{pH} 4.5$ and not $\mathrm{pH} 6.0$, no signal was detected for homoduplex formation of $\mathrm{dA} 8, \mathrm{dA} 16$, or $\mathrm{dA} 24$ strands at either of these $\mathrm{pH}$ values (Fig. 5).

\section{The DNA nanoswitch is a useful tool to accurately detect hetero-dimeric poly(A) duplexes}

\section{Hetero-dimeric poly(rA) duplex formation when interacting strands are of different lengths}

We exploited the ability to change each side of the tested duplex on the DNA nanoswitch to test hetero-stranded du-

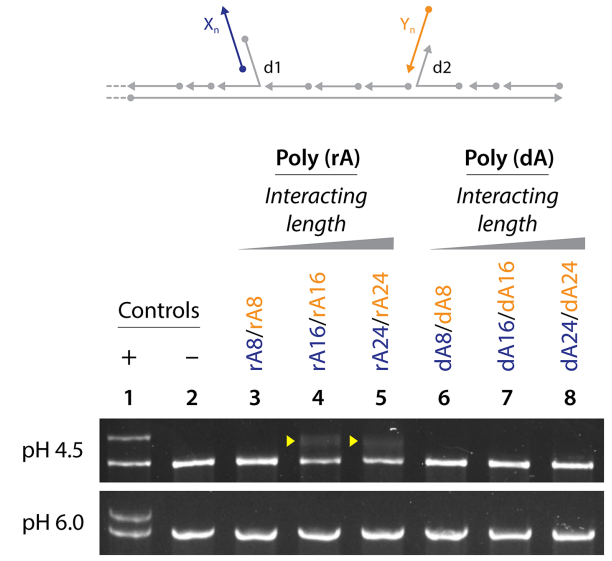

FIGURE 5. Poly(dA) duplexes are not detected by the DNA nanoswitch in conditions of poly $(\mathrm{rA})$ duplex detection. Lanes of interacting oligonucleotides tested and $\mathrm{pH}$ of assays and agarose gels are indicated. For both poly $(\mathrm{rA})$ and poly $(\mathrm{dA})$, we tested interaction lengths $\left(X_{n}\right.$ and $Y_{n}$ ) of 8,16 , and 24 nt on each detector (purple and orange in figure and gel labels, respectively).

plex formations as well as to further evaluate the effectiveness of our method. To test if the smaller side of each construct was limiting to parallel poly(A) duplex formation, and therefore validating the effectiveness of our technique to not include off-target homo-duplex formations in our readout, we performed experiments varying the lengths of interacting poly(rA) strands at a $\mathrm{pH}$ value supporting rA24-rA24 duplex formation, pH 5.0 (Fig. 6A). As expected and now as controls, rA8-rA8 interactions were not detected, whereas rA16-rA16, and rA24-rA24 interactions were detected. Any combination of tested pairs including rA8 as one of the strands, did not produce a detected duplex signal. However, rA16-rA24 duplexes did form, regardless of the detector-side that each strand was positioned (i.e., switching $\mathrm{d} 1$ and $\mathrm{d} 2$ for each strand produced a similar result) (Fig. 6A, lanes 10,11). These results suggest that duplex formation strength is limited by the smaller of the two sides (indicated by gray circles in the bottom panel of Fig. 6A), and this is logical given that the number of bonds capable would be limited by the smaller side. These results also support that the DNA nanoswitch is a detector that is specific for only those strands tested for hetero-duplex formation.

\section{Hetero-dimeric poly(A) duplex formation when strands are of different sugar composition and length}

Antiparallel nucleic acid hetero-duplexes with strands differing in sugar composition form stable helical structures. Many prior studies testing for poly(A) formation often only tested homo-duplex formation, even if modifications were made within each strand. To learn more of the structural adaptability and limitations of the parallel poly $(A)$ helix, we tested for the ability of poly $(r A)$, poly $(m A)$, and poly 
A

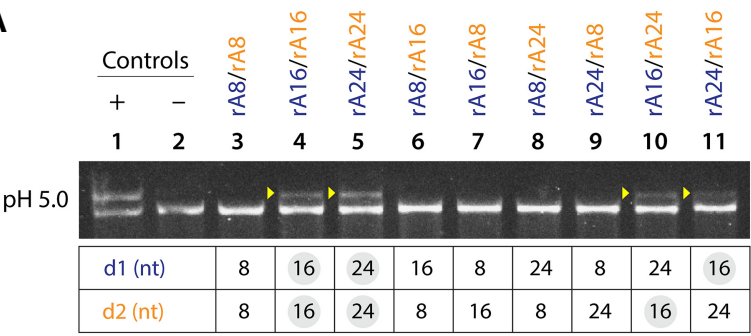

B

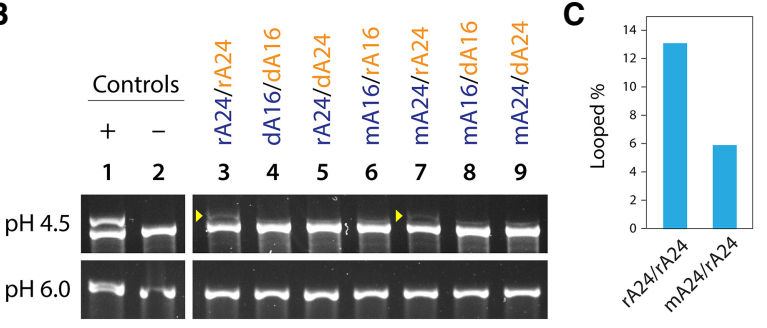

FIGURE 6. Parallel poly(A) hetero-dimeric duplexes can form and be detected by the DNA nanoswitch. Lanes and $\mathrm{pH}$ of assay and gel are indicated. (A) Hetero-dimeric parallel poly(A) duplexes formed from two strands of different lengths is limited by the shorter strand. For the interactions that resulted in parallel duplex formation, the shorter lengths are indicated by a gray circle in bottom panels. (B) Heterodimeric poly $(\mathrm{mA})$-poly $(\mathrm{rA})$ duplexes form when strands are of sufficient length and in acidic conditions (lane 7). Poly(mA)-poly(dA) hetero-duplexes were not detected (lanes 8,9). (C) Histogram of detected fraction of rA24/rA24 and mA24/mA24 looped bands for comparison.

(dA) strands to form hetero-duplexes with one another; combinations of these strands, but each at either 16 nucleotides (nts) or $24 \mathrm{nts}$ in length were tested for interaction at $\mathrm{pH} 4.5$ and $\mathrm{pH} 6.0$ (Fig. 6B). At $\mathrm{pH}$ 6.0, no detection was observed other than positive control K28. Our above results (Fig. 5) showed that at $\mathrm{pH}$ 4.5, rA16 and rA24 homo-duplexes were detected, and homo-duplexes of dA16 and dA24 were not detected. Here, a tested combination for potential rA24-dA24 duplex formation also showed no detection (Fig. 6B, lane 5). Whereas no noticeable detection was observed for an mA16-rA16 heteroduplex (lane 6), an mA24-rA24 hetero-duplex was detected (lane 7) with $\sim 6 \%$ looped nanoswitch compared to $\sim 13 \%$ for the rA24/rA24 homo-duplex (lane 3; Fig. 6C). No detection was observed for an mA16-dA16 or mA24-dA24 hetero-duplex formation (lanes 8 and 9, respectively).

\section{Poly(LNA $A)$ strands duplex strongly with poly(rA) strands but not with other poly(LNAA) strands, and poly(rA)-poly(LNAA) can duplex at a higher $\mathrm{pH}$ than poly $(\mathrm{rA})$ homo-duplexes of the same length}

Sugar moieties in parallel poly(rA) duplexes adopt the C3'endo conformation that is also present in A-form antiparallel RNA duplexes. Since LNA sugar modifications force this conformation, we tested the potential of adenines attached to LNA sugars to contribute to parallel poly(A) duplex formation using our DNA nanoswitch assay. We tested different combinations of strands that contained LNA modifications in acidic conditions (Fig. 7A). Due to limitations in synthesis, our constructs contained a maximum length of 15 sequential LNAA nucleotides. First, we kept one interacting region constant (rA16) and changed the other interacting region to be rA16, rA1-LNA15 (with one rA nucleotide followed by 15 LNA nucleotides) or rA8-LNA8 (with alternating rA and LNA). At pH 6.0, no detection was observed for duplex formations tested (Fig. 7A, bottom gel image). The rA16 homo-duplex was detected at $\mathrm{pH} 5.0$ (as in Fig. 4B), but not at pH 5.5 (Fig. 7A, lane 3). In comparison, a hetero-duplex formed with rA16 and rA1-LNA15 produced an even stronger interaction signal than the rA16 homo-duplex at $\mathrm{pH} 5.0$, and
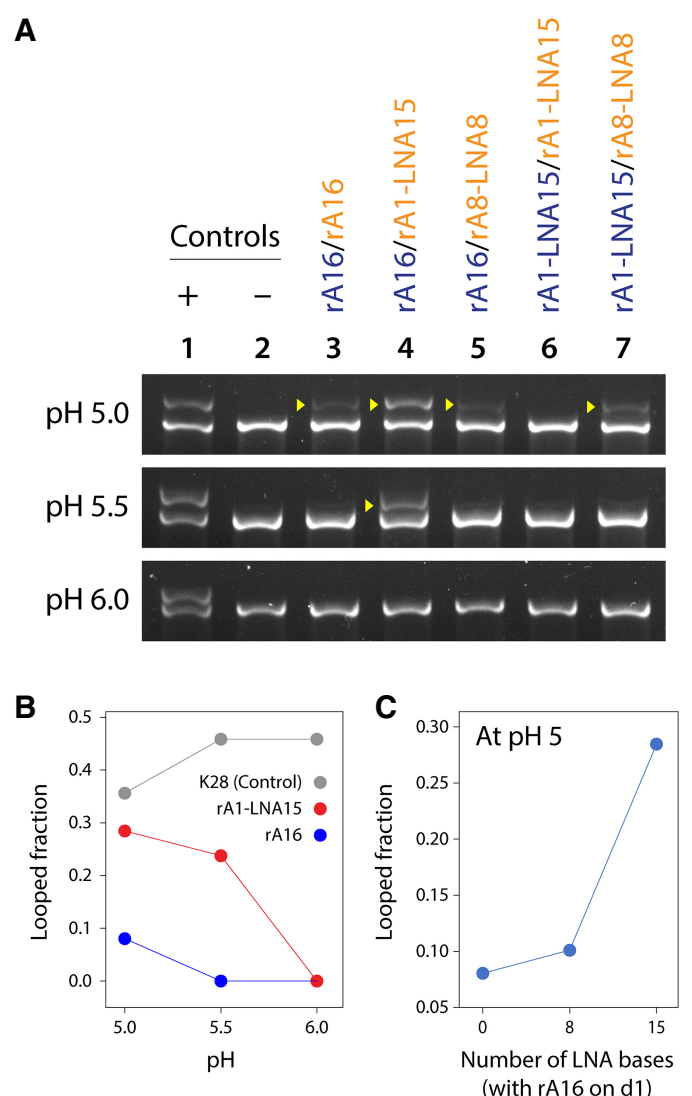

FIGURE 7. Hetero-dimeric poly(LNAA)-poly(rA) duplexes can form in acidic conditions while poly(LNAA)-poly(LNAA) duplexes do not form in these conditions. $(A)$ Interaction regions $(X$ and $Y$ ) on each detector were changed to different combinations of poly $(r A)$ and poly $\left({ }_{L N A} A\right)$ or a mixture of both. Gel results with lanes identified for each type of interaction tested. The $\mathrm{pH}$ of the assay and gel are also indicated. (B) Quantified results of parallel duplex formation at different $\mathrm{pH}$ values for the rA16/rA1-LNA15 and rA16/rA16 combinations. (C) Quantified results of parallel duplex formation at $\mathrm{pH} 5$ for $\mathrm{rA16} /$ rA16 (no LNA bases), rA16/rA8-LNA8 (8 LNA bases), and rA16/rA1LNA15 (15 LNA bases). 
produced a positive interaction signal at $\mathrm{pH} 5.5$ as well (Fig. 7A, lane 4 and Fig. 7B). The strand containing alternating ${ }_{L N A} A$ and $r A$ nucleotides also interacted at $\mathrm{pH} 5.0$ with an rA16 strand, but not at pH 5.5 (Fig. 7A, lane 5). Interestingly, no detection was observed when two poly (LNAA) strands were examined at the $\mathrm{pH}$ values tested (Fig. 7A, lane 6). When a $16 \mathrm{nt}$ strand with alternating LNAA and $r A$ bases was tested for interaction with a poly (LNAA) strand, detection was observed at pH 5.0, but not pH 5.5 (Fig. 7A, lane 7). These results indicate that poly (LNAA) strands bind strongly with poly(rA) strands in a parallel fashion but not with other poly(LNA $A)$ strands, and poly(rA)-poly(LNAA) can duplex at higher $\mathrm{pH}$ values than poly(rA) homo-duplexes of the same length (Fig. 7B). Moreover, within the versions tested, the interactions are stronger with increasing number of LNA nucleotides in the strand that interacts with $\mathrm{AA} 16$ (Fig. 7C).

\section{DISCUSSION}

We have adapted a DNA nanoswitch based method to detect parallel poly(A) duplex formation in acidic conditions and at a sensitivity requiring $10.4 \mathrm{nM}$ of each interacting strand, over 130 times less concentration than typical UV melting studies. As is the benefit of the DNA nanoswitch itself (Koussa et al. 2015; Chandrasekaran et al. 2016), no radiation, spectroscopy equipment, or additional enzymes are required for parallel polyadenylic duplex detection; rather simply, what is required are oligonucleotides and standard DNA agarose gel electrophoresis components and equipment. Additionally, the "on" or "off" state readout while controlling specific strand sequences and compositions being tested for interaction is less ambiguous than native gel analysis. The evidence here that parallel duplex detection with the DNA nanoswitch is $\mathrm{pH}$ dependent strongly suggests that we are indeed analyzing parallel poly(A) duplexes that are known to form in acidic conditions, and that they dissociate as the $\mathrm{pH}$ is increased. We note, however, that the DNA nanoswitch does have its limits, because (i) while producing higher signals at respective acidic $\mathrm{pH}$ values as homo-duplex length increased, respective lengths of detected poly(A) duplexes at $\mathrm{pH} 5.0$ produced a greater fraction of looped signal than at $\mathrm{pH}$ 4.5 (Fig. 4C), and (ii) when normalized to the K28 control (data not shown), the reverse trend was seen, except for rA16 homo-dimer formation testing. It is unclear why these two occurrences were observed; a possible explanation could involve subtle acid-induced destabilization of the nanoswitch and/or detector interactions by depurination or other effects. Additionally, and since it is known that polyadenylic duplexes form in ammonium ion solutions at more neutral pH values (Safaee et al. 2013; Copp et al. 2017), a different limitation to our method is that we currently rely on the presence of phosphate buffered saline (PBS) in our solution and phosphate interacts strongly with ammonium to form an ammonium phosphate salt that would precipitate out of solution. Future development of the method to test a variety of other conditions and metal inclusion as well, would be useful.

Of note, the pKa of $\mathrm{N} 1$ of adenine has been suggested to be 4.2, and 3.64 when part of adenosine (Kapinos et al. 2011). It is N1 protonation that is attributed to parallel polyadenylic helix formation (Rich et al. 1961; Gleghorn et al. 2016). All regions we tested here for interaction contain all adenines as bases and therefore differences in nanoswitch detection levels are reflective of environmental $\mathrm{pH}$, strand lengths, and strand sugar compositions. We are unaware of the pKas for adenine when adjoined to all of the different sugar variants we have used here, and therefore we are for now limited to assume pKas are similar to adenine and adenosine. Parallel poly(rA) homoduplexes were detected with higher signal for rA24formed over $\mathrm{rA} 16$-formed homo-duplexes at acidic $\mathrm{pH}$ values of 4.5 and 5.0 (Fig. 4B,C), values that are both above the $\mathrm{pKa}$ of adenine and adenosine, yet within a $\mathrm{pH}$-range known to support poly(rA) duplex formation in solution (Brahms et al. 1966; Safaee et al. 2013). By definition, pKa reflects an environmental $\mathrm{pH}$ at which a 50:50 mixture of protonated:unprotonated exists, at adenine $\mathrm{N} 1$ in this instance; even at $\mathrm{pH} 5.0$, but not $\mathrm{pH}$ 6.0, protonation appears sufficient for poly(A) duplex formation (Fig. 4). The evidence here and elsewhere (Brahms et al. 1966; Safaee et al. 2013) that longer polyadenylic strands can compensate for lower levels of protonation to form parallel polyadenylic duplexes is very important due to the question of whether such structures exist in cells at more physiological pHs (i.e., near $\mathrm{pH}$ 7). The most obvious place for parallel polyadenylic structures to exist are within the long, poly (rA) tails found in RNA polymerase II transcribed RNAs in cells (Zhao et al. 1999). These tails can be longer than $200 \mathrm{nt}$ in length in eukaryotes (Subtelny et al. 2014), yet it is unclear if the cellular environment can permit their existence. Possibly, at these lengths, a pH near the pKa of adenine $\mathrm{N} 1$ that is required for smaller poly $(r \mathrm{~A})$ sequences to form parallel poly(rA) duplexes, is not as crucial for parallel duplex formation and can be compensated for by having only a few protonated interactions, but more in total due to an increased poly(rA) length. It has been hypothesized that protonation need not derive from solution alone, but possibly from proteins that interact with poly(rA) tails (Zarudnaya and Hovorun 1999).

In addition to protonated adenine, the $\mathrm{C}^{\prime}$-endo sugar pucker observed in nucleotides of solved poly(A) duplex structures appears important to helix stabilization (Safaee et al. 2013; Gleghorn et al. 2016). Evidence for this is first from determined poly(A) parallel helix structures that contained in each strand a single dA substitution that adopted C3'-endo pucker, despite dA typically adopting the $\mathrm{C} 2$ '-endo pucker in a single stranded $\mathrm{dApdA}$ dinucleotide and in poly $(\mathrm{d} A)$ strands antiparallelly 
paired to poly(rU) (Ts'O 1974; Arnott et al. 1986; Erie et al. 1993; Xiong and Sundaralingam 1998; Copp et al. 2017). Secondly, mA incorporation that has been shown to enhance parallel poly(A) duplex stability, achieves this by preferential $\mathrm{C}^{\prime}$-endo pucker observed in the majorly mA-comprised poly(A) helix NMR structure (Copp et al., 2017); this $C 3^{\prime}$-endo preference is sufficient enough to even convert B-form (C2'-endo) DNA antiparallel duplexes to more A-form (C3'-endo) (Lubini et al. 1994; Copp et al. 2017). As such, in our work here, poly(A) parallel duplexes not forming when both strands were poly(dA) (Fig. 5 , lanes 6-8), when one strand was poly $(r A)$ and the other poly(dA) (Fig. 6B, lane 5), and when one strand was poly $(\mathrm{dA})$ and the other poly (mA) (Fig. 6B, lanes 8,9), can be explained by unfavorable C2'-endo sugar pucker, instability of preferred C3'-endo sugar pucker, and/or improper base-stacking interactions. Supporting the latter point, whereas dA substitutions are tolerated and molded to the proper $\mathrm{C}^{\prime}$-endo sugar conformation in the context of otherwise $\mathrm{mA}$ - and rA-containing helices (Copp et al. 2017), our results and those of Copp et al. (2017) that a poly $(\mathrm{dA})$ strand does not support parallel duplex formation, could likely be explained by altered base stacking interactions, in addition to sugar pucker preference, compared to an all rA helix; these differences are evidenced in a single stranded rAprA dinucleotide compared to a dApdA dinucleotide (Ts'O 1974; Erie et al. 1993). Importantly, a poly(mA) strand with nucleotides expected to adopt $C 3^{\prime}$-endo sugar pucker did pair with a poly(rA) strand (Fig. 6B, lane 7) indicating the importance of both strands containing the proper sugar pucker conformations to form the parallel poly $(A)$ helical structure. The looping percentage for this poly $(\mathrm{mA})$-poly $(\mathrm{r} A)$ duplex with 24 possible $A^{+}-A^{+}$pairs was 2.2 times less than for the same length of a poly $(\mathrm{r} A)-$ poly $(r A)$ duplex at $\mathrm{pH} 5.0$ (Fig. 6C); this is in contrast to the 1.9 times enhancement of poly $(m A)$-poly $(m A)$ detection over poly $(r A)-p o l y(r A)$ detection (Fig. 4C). Our results are consistent with the findings of Copp et al. (2017) in that dA-dA pairing does not occur and that $m A-m A$ pairing is more favorable for $\operatorname{poly}(A)$ duplex stability. New here however, with results capable through the advantage that our method provides, is that $m A-r A$ pairing appears less favorable than $r A-r A$ and $m A-m A$ pairing. Since a largely (with a single $d A$ in each strand) $m A$-composed parallel poly $(A)$ helix NMR structure was similar to an all poly $(r A)$ double-helix structure (Copp et al. 2017), it is unclear why mA-mA appears to decrease parallel poly(A) helix stability and/or formation. Possibly, there is subtle disruption in the symmetric nature of the pairs when one is $m A$, and the other $r A$, that owes to a slight decrease in helix stability; however, further structural exploration of this is needed.

Importantly, we have found that at $\mathrm{pH} 5.5$, a poly(LNAA)poly $(r A)$ hetero-duplex can form at an even higher $\mathrm{pH}$ than a poly(rA) homo-duplex of the same length (Fig. 7A, com- pare lanes 3,4; Fig. 7B). Moreover, nanoswitch looping signal increased at $\mathrm{pH} 5.0$ as the number of ${ }_{\text {LNAAs }}$ increased in a strand interacting with a similar length of poly(rA) (Fig. 7C). Possibly, the C $3^{\prime}$-endo prominent and stabilized conformation of this modified sugar supports the parallel duplex formation more so than a poly $(r A)$ sequence, which might have more flexibility. Incorporation of LNA residues in a DNA strand antiparallelly paired with a complementary strand of DNA, causes the resulting helix to adopt a more A-form than B-form conformation (Ivanova and Rösch 2007), illustrating the influence of the LNA-containing strand on the conformation of the entire helical structure. The fact that a poly $\left({ }_{L N} A A\right)-p o l y(r A)$ hetero-duplex strongly forms dependent on acidic $\mathrm{pH}$ in our experiments (Fig. 7), suggests that the duplex is adopting a structure at least some-what similar to the poly $(r A)$ parallel double-helix. It has been shown that LNA-RNA (i.e., one strand containing all LNA residues, and the pairing strand having all ribose sugars) antiparallel and Watson-Crick paired duplexes adopt a helical conformation with parameters that are unlike RNA-RNA and LNA-LNA antiparallel duplexes, and resemble an intermediate conformation between the two (Eichert et al. 2010; Förster et al. 2012). Future structural studies are needed to elucidate the helical parameters of a poly( $\left(N_{A} A\right)-$ poly $(r A)$ parallel double-helix that we have identified here; it will be interesting and informative to then contrast and compare poly(LNAA)poly $(r A)$ and poly $(r A)-p o l y(r A)$ parallel helical parameters.

It is peculiar though, that we did not observe poly(LNAA)poly( (LNA $A$ ) homo-duplex formation (Fig. 7, lane 6). A steric or other hindrance must be preventing $L N A A-\llcorner N A A$ pairing from each strand. Supporting this idea, in Figure 7, the rA1-LNA15/rA8-LNA8 interaction (lane 7) was weaker than rA16/rA1-LNA15 (LNAA-rA pairing) interaction (lane 4), and slightly stronger than the rA16/rA16 interactions. Any positive effect (relative to $\mathrm{rA}-\mathrm{rA}$ interactions) of strong LNAA-rA pairing, is apparently diminished by potentially unfavorable $L N A A-L N A A$ interactions.

Poly $(\mathrm{r} A)$ parallel duplexes at acidic $\mathrm{pH}$ are stabilized by inter-strand rA-rA base-base pairing, as well as basephosphate interactions (Rich et al. 1961; Gleghorn et al. 2016). Direct base-phosphate inter-strand interactions are absent in RNA-RNA, LNA-RNA, LNA-LNA, DNADNA, and DNA-RNA antiparallel duplexes that are formed largely through Watson-Crick base-base inter-strand interactions. Inherent to the pairing that generates the poly $(\mathrm{r} A)$ parallel double-helix, while having C3'-endo sugar pucker, helical parameters are otherwise unlike that of A-form antiparallel double helices (Safaee et al. 2013; Gleghorn et al. 2016). Factors specific to LNA residues must therefore contribute to preventing poly( $\left({ }_{N A} A\right)-$ poly $(\llcorner N A A)$ parallel duplex formation despite the preferred $\mathrm{C}^{\prime}$ '-endo sugar pucker from both strands. Molecular modeling and structural studies have shown that LNA-LNA antiparallel helices are underwound due to competing forces of steric rigidity 
and base-stacking interactions (Pande and Nilsson 2008; Förster et al. 2012; Yildirim et al. 2014). Possibly, without one strand of an "all poly(LNA $A$ )" parallel duplex having the conformational dexterity to accommodate the rigidity of the other, like the more flexible poly(rA), improper base-stacking and pairing interactions do not support the protonated N1-mediated interactions necessary for the duplex to form at acidic pH (Fig. 1). Consistent with there being a limit to LNA-induced enhancement to helical stability, TFO strands composed of all LNAs were unable to support triplex formation with a dsDNA, whereas LNA substitutions within an otherwise DNA strand showed enhanced triplex formation over a natural DNA TFO at pH 6.6 and 7.2 (Obika et al. 2001).

Although we can learn from LNA incorporation in antiparallel Watson-Crick paired duplexes, it is important to note that our knowledge of these helical formations is not necessarily directly transferable to our understanding of parallel poly(A) duplexes. This is evidenced by our results showing that a poly(dA) strand does not detectably pair with a poly(rA) strand (Fig. 6B, lane 5), since DNARNA antiparallel duplexes are well known to form. As such, and with our current state of knowledge, it is difficult to predict the resulting helical structure and parameter values that will form when one strand has different modification than the other.

In conclusion, the work presented here presents a DNA nanoswitch based method that can be developed further in the future to detect other $\mathrm{pH}$-sensitive nucleic acid interactions, such as i-motif and triplex structures. Our findings suggest that $\mathrm{C}^{3}$-endo pucker is an important structural element to parallel poly(A) duplex formation. Moreover, we have identified a potential poly $(r A)$ duplex mimic, poly ( $r A)-p o l y(L N A A)$ that can form at a $\mathrm{pH}$ higher than that of a poly $(r A)$ duplex of similar length. Our immediate hope is that we can use our knowledge of the poly(rA)-poly(LNA $A$ ) duplex to capture mature poly(rA)-tailed mRNA transcripts in a method that can be compared to the existing oligo(dT)and cap-based methods (Blower et al. 2013). Such a strategy could have benefits over traditional oligo(dT) based purification, especially since extraction of RNA from cells already requires low $\mathrm{pH}$ to purify RNA away from DNA (Chomczynski and Sacchi 2006), and this, the nature of the poly $(A)$ duplex, and the incorporation of LNA molecules could provide RNase resistance. A stable poly(rA) duplex mimic might also be used as a tool to identify proteins in cells that can potentially recognize this structure.

\section{MATERIAL AND METHODS}

\section{Construction of the DNA nanoswitch for parallel duplex detection}

DNA nanoswitches were constructed as described in Chandrasekaran et al. (2016) (without purification) to contain detector D1 and D2 (here referred to as " $\mathrm{d} 11^{* \prime}$ " and " $\mathrm{d} 2$ " ", respectively) sequences at variable V4 and V8 positions on the nanoswitch with appropriate filler strands (Chandrasekaran et al. 2016). All oligos were purchased from Integrated DNA Technologies, except those containing LNA (i.e., 2'-O-4'-C-methylene- $\beta$-D-ribofuranosyl) modifications, which were purchased from Qiagen. All oligos were purchased with a standard desalting purification level. Once the nanoswitches were built by annealing, the mixture was diluted 1:25 in a 1× PBS annealing buffer at the $\mathrm{pH}$ tested in the subsequent assay, that is, "detection buffer." Oligomers used for testing duplex interactions (Table 1) contained a tested region for interaction as well as a $14 \mathrm{nt}$ sequence that is the reverse complement of $\mathrm{d} 1^{*}$ or $\mathrm{d} 2^{*}$ detector arms; this region is one-half of the K28 sequence described in Chandrasekaran et al. (2016). Each individual oligo used for detection was diluted to $50 \mathrm{nM}$ in the specific detection buffer yielding a concentration of $25 \mathrm{nM}$ after combining $25 \mu \mathrm{L}$ of each oligo. A single oligonucleotide, "K28" that binds to $14 \mathrm{nt}$ from each detector arm served as a positive control for detection (Chandrasekaran et al. 2016). The 50 $\mu \mathrm{L}$ solution of mixed oligos for interaction detection were annealed, along with the annealing for assembly of the nanoswitch itself (Chandrasekaran et al. 2016), in a T100 Bio-Rad thermocycler, by heating the mixture to $90^{\circ} \mathrm{C}$ and then cooling at a rate of $1^{\circ} \mathrm{C}$ per minute to $4^{\circ} \mathrm{C}$ (Chandrasekaran et al. 2016). Oligos were then transferred to ice and $5 \mu \mathrm{L}$ was mixed with $5 \mu \mathrm{L}$ of prechilled diluted nanoswitch in prechilled $0.2 \mathrm{~mL}$ PCR tubes, vortexed, and centrifuged on a table-top centrifuge and incubated $\sim 7$ to $17 \mathrm{~h}$ in the refrigerator at $4^{\circ} \mathrm{C}$.

\section{Acidic $\mathrm{pH}$ agarose gel electrophoresis and nanoswitch readout}

Following the completion of the detection assay $2 \mu \mathrm{L}$ of cold $6 \times$ DNA loading dye with bromophenol blue and xylene cyanol was added to each tube. Samples were immediately separated on a $0.8 \%$ agarose gel made with a $0.05 \mathrm{M}$ citrate buffer with $\mathrm{pH}$ values of: $4.5,5.0,5.5$, or 6.0. The $\mathrm{pH}$ of the gel buffer always matched the $\mathrm{pH}$ of the $1 \times$ PBS used in the detection assay. Gels $(40 \mathrm{~mL})$ were prestained with $2 \mu \mathrm{L}$ of $10,000 \times$ GelRed. Acidic gels were separated in a refrigerator at $40 \mathrm{~V}$ for 4-8 h on ice using prechilled buffer of the same $\mathrm{pH}$ as the gel; the gel and gel box were also prechilled and ice packs placed on top of the gel box to absorb as much heat as possible to aid in preventing denaturation of the parallel poly(A) duplexes and overheating of the gel (Liu et al. 1993). Gels were imaged on a Bio-Rad ChemiDoc XRS+ or ChemiDoc MP gel imager with associated Image Lab Software (versions 6.0.1.34 and 5.2.1, respectively), that was also used for quantifying band intensities.

\section{ACKNOWLEDGMENTS}

This work was supported by RIT College of Science start-up funds and by an RIT Grant Writers' Bootcamp Seed Funding award. We thank Michael Savka and André Hudson for use of imaging instrumentation and associated software in their laboratory.

Received March 14, 2020; accepted May 4, 2020. 


\section{REFERENCES}

Arnott S, Chandrasekaran R, Millane RP, Park HS. 1986. DNA-RNA hybrid secondary structures. J Mol Biol 188: 631-640. doi:10.1016/ S0022-2836(86)80011-0

Baeyens KJ, De Bondt HL, Pardi A, Holbrook SR. 1996. A curved RNA helix incorporating an internal loop with G.A and A.A nonWatson-Crick base pairing. Proc Natl Acad Sci 93: 1285112855. doi:10.1073/pnas.93.23.12851

Blower MD, Jambhekar A, Schwarz DS, Toombs JA. 2013. Combining different mRNA capture methods to analyze the transcriptome: analysis of the Xenopus laevis transcriptome. PLoS One 8: e77700. doi:10.1371/journal.pone.0077700

Brahms J, Michelson AM, Van Holde KE. 1966. Adenylate oligomers in single- and double-strand conformation. J Mol Biol 15: 467488. doi:10.1016/S0022-2836(66)80122-5

Chakraborty S, Sharma S, Maiti PK, Krishnan Y. 2009. The poly dA helix: a new structural motif for high performance DNA-based molecular switches. Nucleic Acids Res 37:2810-2817. doi:10.1093/nar/gkp133

Chandrasekaran AR, Zavala J, Halvorsen K. 2016. Programmable DNA nanoswitches for detection of nucleic acid sequences. ACS Sensors 1: 120-123. doi:10.1021/acssensors.5b00178

Chandrasekaran AR, Levchenko O, Patel DS, Maclsaac $M$, Halvorsen K. 2017. Addressable configurations of DNA nanostructures for rewritable memory. Nucleic Acids Res 45: 11459-11465. doi:10.1093/nar/gkx777

Chandrasekaran AR, Maclsaac M, Dey P, Levchenko O, Zhou L, Andres M, Dey BK, Halvorsen K. 2019. Cellular microRNA detection with miRacles: microRNA-activated conditional looping of engineered switches. Sci Adv 5: eaau9443. doi:10.1126/sciadv.aau9443

Chomczynski P, Sacchi N. 2006. The single-step method of RNA isolation by acid guanidinium thiocyanate-phenol-chloroform extraction: twenty-something years on. Nat Protoc 1: 581-585. doi:10 .1038 /nprot.2006.83

Copp W, Denisov AY, Xie J, Noronha AM, Liczner C, Safaee N, Wilds CJ, Gehring K. 2017. Influence of nucleotide modifications at the $\mathrm{C}^{\prime}$ position on the Hoogsteen base-paired parallel-stranded duplex of poly(A) RNA. Nucleic Acids Res 45: 10321-10331. doi:10.1093/nar/gkx713

Day HA, Pavlou P, Waller ZA. 2014. i-Motif DNA: structure, stability and targeting with ligands. Bioorg Med Chem 22: 4407-4418. doi:10.1016/j.bmc.2014.05.047

Devi G, Zhou Y, Zhong Z, Toh DF, Chen G. 2015. RNA triplexes: from structural principles to biological and biotech applications. Wiley Interdiscip Rev RNA 6: 111-128. doi:10.1002/wrna.1261

Eichert A, Behling K, Betzel C, Erdmann VA, Fürste JP, Förster C. 2010. The crystal structure of an 'All Locked' nucleic acid duplex. Nucleic Acids Res 38: 6729-6736. doi:10.1093/nar/gkq505

Erie DA, Breslauer KJ, Olson WK. 1993. A Monte Carlo method for generating structures of short single-stranded DNA sequences. Biopolymers 33: 75-105. doi:10.1002/bip.360330109

Förster C, Eichert A, Oberthür D, Betzel C, Geßner R, Nitsche A, Fürste JP. 2012. Features of "All LNA" duplexes showing a new type of nucleic acid geometry. J Nucleic Acids 2012: 156035. doi:10.1155/2012/156035

Gleghorn ML, Zhao J, Turner DH, Maquat LE. 2016. Crystal structure of a poly $(\mathrm{rA})$ staggered zipper at acidic $\mathrm{pH}$ : evidence that adenine N1 protonation mediates parallel double helix formation. Nucleic Acids Res 44: 8417-8424. doi:10.1093/nar/gkw526

Ivanova A, Rösch N. 2007. The structure of LNA:DNA hybrids from molecular dynamics simulations: the effect of locked nucleotides. J Phys Chem A 111: 9307-9319. doi:10.1021/jp073198j

Jain A, Wang G, Vasquez KM. 2008. DNA triple helices: biological consequences and therapeutic potential. Biochimie 90: 11171130. doi:10.1016/j.biochi.2008.02.011
Joung IS, Persil Cetinkol O, Hud NV, Cheatham TE. 2009. Molecular dynamics simulations and coupled nucleotide substitution experiments indicate the nature of A.A base pairing and a putative structure of the coralyne-induced homo-adenine duplex. Nucleic Acids Res 37: 7715-7727. doi:10.1093/nar/gkp730

Kapinos LE, Operschall BP, Larsen E, Sigel H. 2011. Understanding the acid-base properties of adenosine: the intrinsic basicities of N1, N3 and N7. Chemistry (Easton) 17: 8156-8164. doi:10 .1002/chem.201003544

Koussa MA, Halvorsen K, Ward A, Wong WP. 2015. DNA nanoswitches: a quantitative platform for gel-based biomolecular interaction analysis. Nat Methods 12: 123-126. doi:10.1038/nmeth.3209

Kumar N, Nielsen JT, Maiti S, Petersen M. 2007. i-Motifformation with locked nucleic acid (LNA). Angew Chem Int Ed Engl 46: 9220 9222. doi:10.1002/anie.200701667

Liu K, Miles HT, Frazier J, Sasisekharan V. 1993. A novel DNA duplex. A parallel-stranded DNA helix with Hoogsteen base pairing. Biochemistry 32: 11802-11809. doi:10.1021/bi00095a008

Lubini P, Zürcher W, Egli M. 1994. Stabilizing effects of the RNA 2'substituent: crystal structure of an oligodeoxynucleotide duplex containing 2'-O-methylated adenosines. Chem Biol 1: 39-45. doi:10.1016/1074-5521(94)90039-6

Obika S, Uneda T, Sugimoto T, Nanbu D, Minami T, Doi T, Imanishi T. 2001. 2'-O,4'-C-Methylene bridged nucleic acid (2',4'-BNA): synthesis and triplex-forming properties. Bioorg Med Chem 9: 1001-1011. doi:10.1016/S0968-0896(00)00325-4

Pande V, Nilsson L. 2008. Insights into structure, dynamics and hydration of locked nucleic acid (LNA) strand-based duplexes from molecular dynamics simulations. Nucleic Acids Res 36: 1508-1516. doi:10.1093/nar/gkm1182

Persil O, Santai CT, Jain SS, Hud NV. 2004. Assembly of an antiparallel homo-adenine DNA duplex by small-molecule binding. J Am Chem Soc 126: 8644-8645. doi:10.1021/ja0492891

Pettersen EF, Goddard TD, Huang CC, Couch GS, Greenblatt DM, Meng EC, Ferrin TE. 2004. UCSF Chimera-a visualization system for exploratory research and analysis. J Comput Chem 25: 16051612. doi:10.1002/jcc.20084

Rich A, Davies DR, Crick FH, Watson JD. 1961. The molecular structure for polyadenylic acid. J Mol Biol 3: 71-86. doi:10.1016/ S0022-2836(61)80009-0

Safaee N, Noronha AM, Rodionov D, Kozlov G, Wilds CJ, Sheldrick GM, Gehring K. 2013. Structure of the parallel duplex of poly(A) RNA: evaluation of a 50 year-old prediction. Angew Chem Int Ed Engl 52: 10370-10373. doi:10.1002/anie.201303461

Subtelny AO, Eichhorn SW, Chen GR, Sive H, Bartel DP. 2014. Poly(A)tail profiling reveals an embryonic switch in translational control. Nature 508: 66-71. doi:10.1038/nature13007

Szabat M, Kierzek R. 2017. Parallel-stranded DNA and RNA duplexes -structural features and potential applications. FEBS J 284: 3986-3998. doi:10.1111/febs.14187

Szabat M, Pedzinski T, Czapik T, Kierzek E, Kierzek R. 2015. Structural aspects of the antiparallel and parallel duplexes formed by DNA, 2'-O-methyl RNA and RNA oligonucleotides. PLoS One 10: e0143354. doi:10.1371/journal.pone.0143354

Ts'O POP. 1974. 6-Bases, nucleosides, and nucleotides. In Basic principles in nucleic acid chemistry (ed. Ts'O POP), pp. 453-584. Academic Press, New York.

Vester B, Wengel J. 2004. LNA (locked nucleic acid): high-affinity targeting of complementary RNA and DNA. Biochemistry 43: 13233-13241. doi:10.1021/bi0485732

Xing F, Song G, Ren J, Chaires JB, Qu X. 2005. Molecular recognition of nucleic acids: coralyne binds strongly to poly(A). FEBS Lett 579: 5035-5039. doi:10.1016/j.febslet.2005.07.091

Xiong Y, Sundaralingam M. 1998. Crystal structure and conformation of a DNA-RNA hybrid duplex with a polypurine RNA strand: $d$ 
(TTCTTBr ${ }^{5}$ CTTC)-r(GAAGAAGAA). Structure 6: 1493-1501. doi:10.1016/S0969-2126(98)00148-8

Yatsunyk LA, Mendoza O, Mergny JL. 2014. "Nano-oddities": unusual nucleic acid assemblies for DNA-based nanostructures and nanodevices. Acc Chem Res 47: 1836-1844. doi:10.1021/ar500063x

Yildirim I, Kierzek E, Kierzek R, Schatz GC. 2014. Interplay of LNA and 2'-O-methyl RNA in the structure and thermodynamics of RNA hybrid systems: a molecular dynamics study using the revised AMBER force field and comparison with experimental results. J Phys Chem B 118: 14177-14187. doi:10.1021/ jp506703g
Zarudnaya MI, Hovorun DM. 1999. Hypothetical double-helical poly (A) formation in a cell and its possible biological significance. IUBMB Life 48: 581-584. doi:10.1080/713803577

Zeraati M, Langley DB, Schofield P, Moye AL, Rouet R, Hughes WE, Bryan TM, Dinger ME, Christ D. 2018. I-motif DNA structures are formed in the nuclei of human cells. Nat Chem 10: 631-637. doi:10.1038/s41557-018-0046-3

Zhao J, Hyman L, Moore C. 1999. Formation of mRNA 3' ends in eukaryotes: mechanism, regulation, and interrelationships with other steps in mRNA synthesis. Microbiol Mol Biol Rev 63: 405-445. doi:10.1128/MMBR.63.2.405-445.1999 

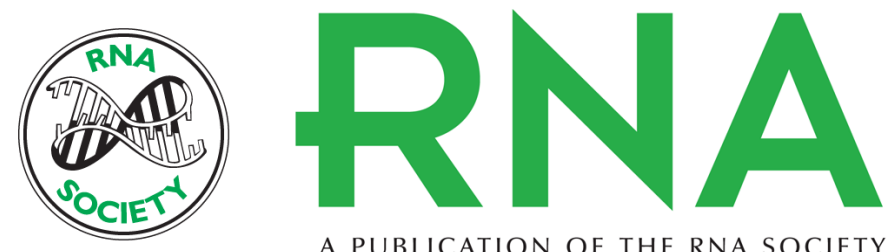

A PUBLICATION OF THE RNA SOCIETY

\title{
Parallel poly $(\mathrm{A})$ homo- and hetero-duplex formation detection with an adapted DNA nanoswitch technique
}

\author{
Martha Anne G. Pickard, Karl B. Brylow, Lily A. Cisco, et al.
}

RNA 2020 26: 1118-1130 originally published online May 15, 2020

Access the most recent version at doi:10.1261/rna.075408.120

\section{References This article cites 41 articles, 3 of which can be accessed free at: http://rnajournal.cshlp.org/content/26/9/1118.full.html\#ref-list-1 \\ Creative This article is distributed exclusively by the RNA Society for the first 12 months after the Commons full-issue publication date (see http://rnajournal.cshlp.org/site/misc/terms.xhtml). After 12 License months, it is available under a Creative Commons License (Attribution-NonCommercial 4.0 International), as described at http://creativecommons.org/licenses/by-nc/4.0/.}

Email Alerting Receive free email alerts when new articles cite this article - sign up in the box at the Service top right corner of the article or click here.

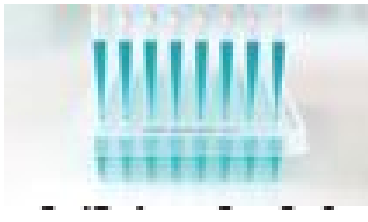

\section{Providing Precise Solutions for} your research.

To subscribe to $R N A$ go to:

http://rnajournal.cshlp.org/subscriptions 